\title{
Lateral Asymmetries in Infant Melody Perception
}

\author{
Marie T. Balaban \\ Johns Hopkins University
}

\author{
Linda M. Anderson \\ Harvard University
}

\author{
Amy B. Wisniewski \\ Johns Hopkins University
}

\begin{abstract}
Two experiments investigated lateral asymmetries in infants' perception of contour-altered and contour-preserved melody changes. In the first study, 40 infants $(8.5$ months old $)$ of right-handed parents were trained to respond to binaural melody changes with a head turn toward mechanized toy reinforcers. The subsequent test phase included monaural left-ear and right-ear presentations of the familiar melody and of a changed melody. Infants who heard a contour-altered change showed a left-ear advantage, whereas infants who heard a contour-preserved change showed a right-ear advantage. These effects were replicated with a different set of melodies in the second study. The pattern of lateralization for detection of melody changes in infants of right-handed parents resembles that previously found in right-handed adults and may reflect more general hemispheric processing differences in the early organization of auditory information processing.
\end{abstract}

Lateral asymmetries in perception exist across modalities and across species and often reflect specialization of processing in the cerebral hemispheres (see Hellige, 1993, for a review). Initial characterizations of broad distinctions between hemispheres have been supplanted by the notion that more precise definitions of the components of perceptual and cognitive processes are necessary to advance our understanding of lateralized neural function. From a developmental perspective, it is likely that knowledge about the maturational course of neural asymmetries will provide clues regarding the functional maturity of underlying processing systems. How do cerebral asymmetries unfold across development?

Questions concerning the ontogeny of neural asymmetries have changed dramatically over the past three decades. For example, it was once thought that neural asymmetry did not exist in prelingual children (Lenneberg, 1967) and that asymmetry reflected greater cognitive ability and specialization (see Hiscock \& Kinsbourne, 1995). Together, these two assumptions contributed to the belief that cerebral laterality develops

Marie T. Balaban and Amy B. Wisniewski, Department of Psychology, Johns Hopkins University; Linda M. Anderson, Department of Psychology, Harvard University.

Portions of this research were presented at the 1994 International Conference on Infant Studies, Paris, and at the 1994 International Conference on Music Perception and Cognition, Liege, Belgium. The experiments were partially supported by funds from the Department of Psychology, Harvard University. We thank all of our infant and parent participants, and we gratefully acknowledge the laboratory assistants who helped with this project, especially Pamela McCarthy and Shireen Boulos at Harvard University and Jacqueline Fewkes, Mika Osada, and Samantha Marks at Johns Hopkins University. We also thank Trisha Van Zandt, Tim Brown, and Dave Scrams for their valuable comments.

Correspondence concerning this article should be addressed to Marie T. Balaban, who is now at the Department of Psychology, Eastern Oregon University, 1410 'L" Avenue, La Grande, Oregon 97850. throughout the human life span and is not characteristic of mental functioning in infants or young children. Current theoretical and empirical accounts suggest that asymmetries in brain structure and lateralization of perceptual and cognitive processing exist at or prior to birth (Huttenlocher, 1993; LeMay \& Culebras, 1972; Previc, 1991) and unfold rather than develop. This prevailing ontogenetic theory of asymmetry is one in which patterns of lateralization are constant throughout life, coupled with increasing cognitive ability and decreasing functional plasticity (Kinsbourne \& Hiscock, 1977; Witelson, 1987). In other words, perceptual, cognitive, and motor asymmetries observed in adults would be expected to occur in infants and young children as soon as they demonstrate proficiency in tasks designed to measure functional asymmetries within these domains.

Research on lateral asymmetries during infancy has traditionally focused on information processing tasks that vary along broad functional dichotomies (Bradshaw \& Nettleton, 1983). In the auditory domain, studies have primarily contrasted the processing of speech versus nonspeech stimuli (often music). The typical pattern of lateralization reported in these studies is a right-ear/left-hemisphere advantage for speech and a left-ear/ right-hemisphere advantage for music (Bertoncini et al., 1989; Best, 1988; Molfese \& Molfese, 1979). For example, when sounds were presented directly behind them, neonates were more likely to turn their heads to the right during presentation of speech and to the left during music, suggesting an early lefthemisphere bias for speech perception and right-hemisphere bias for music perception (Young \& Gagnon, 1990). In a discrimination task, 3- and 4-month-old infants showed a right-ear advantage for speech syllables and a left-ear advantage for musical notes; 2-month-olds showed only the left-ear advantage for $\mathrm{mu}$ sic (Best, Hoffman, \& Glanville, 1982).

A componential approach toward understanding behavioral asymmetries and their underlying neural circuits recognizes that asymmetries for various components comprising a single per- 
ceptual or cognitive task can vary in both direction and degree (Hellige, 1993). For example, in adults, in contrast to an overall right-ear advantage for speech, left-ear advantages have been reported for certain aspects of speech processing, such as prosody or stress (Behrens, 1985; Ross, 1985; Shipley-Brown, Dingwall, Berlin, Yeni-Komshian, \& Gordon-Salant, 1988). Adult patterns of lateralization discussed here focus on populations in which right-handedness was explicitly assessed or can indirectly be inferred because of the prevalence of right-handed individuals in the overall population. Rescarch on visual hemispheric asymmetries in adults also supports the usefulness of a components approach. Asymmetries differ in degree and direction for subsystems comprising a single task such as visuospatial processing (Kosslyn et al., 1989; Kitterle, Hellige, \& Christman, 1992).

The study of the developmental unfolding of lateral asymmetries may help delineate subsystems of perceptual processing in infants. Researchers measuring infants' auditory-evoked responses report hemispheric dissociations in the processing of different components of synthesized speech (Molfese \& Molfese, 1979, 1980). The pattern of visual field advantages in infants also suggests that multiple subsystems underlie object processing. For example, discrimination of shape of visual patterns in 4- to 10-month-old infants was superior in the right visual field-left hemisphere, and discrimination of location was superior in the left visual field-right hemisphere (Deruelle \& de Schonen, 1991, 1995). Although few infant studies attempt to measure asymmetry for specific components comprising perceptual tasks, this approach is essential to an understanding of the development of neural asymmetries. In this article, we extend the study of lateralization to components of music processing in infants at 8.5 months of age. We believe that these results provide new insight into early patterns of hemispheric specialization for auditory information processes previously assumed to be right-hemisphere dominant.

Music perception involves multiple processes, and it is important to consider whether the patterns of lateral asymmetry vary across component processes (Peretz, 1993). In the current studies, we examined lateralization in infants' abilities to discriminate contour-preserved and contour-altered changes in melody. A melody is comprised of musical notes, and relationships among notes can be described either locally or globally. At a local level, the pitch of each musical note is determined by its frequency; the pitch distance between two adjacent notes is known as an interval. At a global level, melodic contour describes the shape of the melody, that is, the overall pattern of ascending and descending pitches (Dowling, 1978, 1982; Dowling \& Harwood, 1986; Morrongiello, 1988; Trehub, Trainor, \& Unyk, 1993). Thus, as shown in Figure 1, one can change the component pitches and intervals in a melody in a way that preserves the contour of the original melody (a contour-preserved change) or in a way that alters the contour (a contouraltered change).

This distinction between contour-preserved and contour-altered components of musical processing is reflected in different patterns of lateral asymmetry for melody discrimination in adults. That is, patterns of lateralization differ in adults, depending on whether contour information or interval information is emphasized. There is converging evidence for hemispheric specialization from studies of normal adults and from neuropsy-

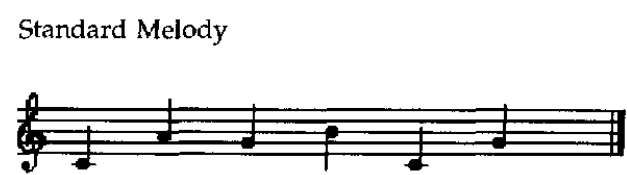

Contour-Preserved Melody

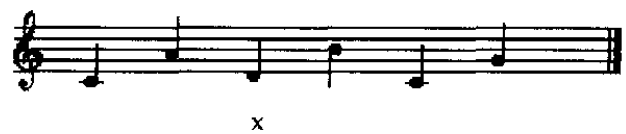

Contour-Altered Melody

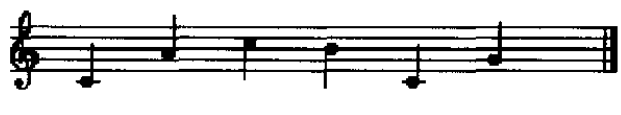

$x$

Figure 1. Compare the contour-preserved and contour-altered melody changes to the sample standard melody. In the contour-preserved change, a change in the third note does not alter the shape of the melody in terms of direction. In the contour-altered melody change, a change in the third note of the melody does alter the shape of the melody.

chological studies. In studies of adults, a left-ear/right-hemisphere advantage has been found for the detection of changes to melodies that alter melodic contour, and a right-car/left-hemisphere advantage for changes that preserve melodic contour and change only the relation of adjacent notes (e.g., Anderson, 1994; Peretz, 1987; Peretz \& Morais, 1980). This pattern also occurred in patients with unilateral left-hemisphere damage; however, patients with right-hemisphere damage showed deficits in discriminating both contour-altered and contour-preserved melody changes (Peretz, 1990). Peretz (1993) proposed that the latter result reveals that "the extraction of contour was a preliminary and indispensable step to the precise encoding of intervals' (p. 219). Therefore, converging evidence suggests that contour-preserved and contour-altered melodic changes are processed differently in adults, but it is conceivable that these component processes are hierarchically organized in normal functioning.

We know that infants as young as 81011 months of age can detect both contour-altered and contour-preserved changes to melodies (Trehub, Bull, \& Thorpe, 1984). Infant melody perception is typically studied with a visually reinforced audiometry procedure. The infants hear repetitions of a standard auditory stimulus (e.g., a melody) and are trained to turn their head when a change occurs in this auditory stimulus. When they correctly turn their head to a change, a mechanized toy is activated for several seconds. In one study, infants responded to contour-altered melody changes, contour-preserved melody changes, and transpositions of the melody to another musical key (Trehub et al., 1984). Responses to the contouraltered changes were more accurate than responses to the contour-preserved changes, such that infants were more likely to confuse contour-preserved changes with the standard melody than they were to confuse contour-altered changes with the 
standard melody. Trehub and her colleagues (Trehub, 1993; Trehub \& Trainor, 1990) therefore suggested that although infants can detect both contour-altered and contour-preserved changes to melodies, they rely more on contour-altered changes when task demands are increased. Infants detected even a one-note change within a melody when that change altered the melodic contour of the original melody (Trehub, Thorpe, \& Morrongiello, 1985). At 9 to 11 months, infants discriminated changes in melodic contour, despite irrelevant variations in interval size or absolute frequency (Trehub, Thorpe, \& Morrongiello, 1987). Using a novelty preference paradigm, Ferland and Mendelson (1989) obtained similar results with 10 -month-old infants. The infants could detect changes in tones differing in frequency or waveform; however, they ignored these changes and treated auditory sequences as equivalent if the sequences had the same melodic contour.

These studies of melody and speech perception in infants and adults provided the framework for our studies of hemispheric specialization of infant melody perception. If there are functional lateral asymmetries in melody processing during infancy, different patterns of performance seem plausible on the basis of past and present theories of neural asymmetries. For example, one alternative is that infants would show a left-ear/right-hemisphere advantage for melody changes, regardless of whether those changes are contour altered or contour preserved. Such a pattern would suggest that an overall right-hemisphere specialization for music exists early in development as a precursor to a later, more differentiated response to components of melody processing. An alternative prediction is that infants would show the pattern typical of right-handed adults - that is, left-ear advantages for contour-altered melody changes and right-ear advantages for contour-preserved melody changes-if the processes involved in each of these types of melody discrimination are already functionally lateralized.

To investigate lateralization in infants' detection of contouraltered and contour-preserved melody changes, we used the well-established head-turn paradigm adopted by Trehub and her colleagues (e.g., Trehub et al., 1984). In the typical visually reinforced head-turn procedure, the sound source is a speaker located near the mechanized reinforcer. This match between the localization of the sound source and the visual location of the toy takes advantage of the infants' tendency to orient toward sound and sound changes. Because we were interested in lateralization, it was necessary in our experiments for the sound to be presented to the infant through headphones to allow for monaural melody presentations, thus eliminating the direct association between the sound source and the toy reinforcer. During pilot testing, it became apparent that infants were able to learn the task, despite the lack of direct association between the sound source and the visual reinforcer. However, to do so, the infants required a relatively long period of training.

We chose to test infants at the age of 8.5 months for several reasons: Infants at this age can detect both contour-altered and contour-preserved melody changes (Trehub et al., 1984). They are also within the age range in which hemispheric specialization for components of visual pattern processing has been demonstrated (Deruelle \& de Schonen, 1995). Finally, our pilot studies indicated that training was difficult for younger infants ( 7 months) in the visually reinforced audiometry task, when melodies were presented via headphones. We limited the main analyses to infants whose parents were both right-handed. This decision was made because hemispheric lateralization is often weaker or more variable in left-handed adults (Coren, 1990), and left-handedness is more prevalent for children with one or two left-handed parents than for children with two right-handed parents (McManus \& Bryden, 1991).

\section{Experiment 1}

\section{Method}

\section{Participants}

Forty healthy infants, 20 girls and 20 boys, with a mean age of 8.5 months (range 8.0 to 9.0 months), were included in the primary sample. None of the infants had known hearing problems. Both parents of each infant were right-handed. Nine additional participants had at least one left-handed parent. Their results were combined with infants with lefthanded parent $(s)$ in the second study and described separately, following Experiment 2 results. Another 10 infants were excluded from the study because of equipment failure ( $n=2)$ or because the infant did not reach the training criterion $(n=5)$ or did not complete the study because of fussiness $(n=3)$. Infants were recruited in the Boston area through newspaper advertisements and through letters sent to parents identified from state or published birth records.

\section{Apparatus}

Melodies were generated by a MacIntosh computer (Powerbook 160) and were output through a stereo amplifier to lightweight Panasonic personal stereo headphones. Loudness of the tones was calibrated steadystate to approximately $70 \mathrm{~dB}$ (A) with a GenRad (1565-B, Quad Tech, Woburn, MA) sound level meter. ${ }^{1}$ The computer and stereo amplifier were located in a control room, and the infant was tested in an adjacent room. Masking music for the parent and the experimenter was presented through two sets of headphones via a separate stcreo system in the test room.

Three mechanized toys served as visual reinforcers during the experiment (a pig, an elephant with cymbals, and a character popping up from a trash can). These toys were housed in a case that was $81 \mathrm{~cm}$ tall and $92 \mathrm{~cm}$ wide, located to the left or right side of the infant at a distance of approximately $75 \mathrm{~cm}$. The case had six compartments, three across the top and three across the bottom, and one toy was placed in each top compartment. The case was covered with opaque plexiglass so that the toys were visible only when their compartment was lit and the toy was activated. The side of the toy case (to the left or the right of the infant) was counterbalanced across infants. Toys were activated by switches in the control room.

\section{Stimuli}

The stimuli consisted of six-note tonal melodies, modeled after those used by Trehub et al. (1984). Each note was a $200-\mathrm{ms}$ sine wave tone with a rise and fall time of $30 \mathrm{~ms}$. Interstimulus intervals were $200 \mathrm{~ms}$ between notes and $800 \mathrm{~ms}$ between melodies. There were a total of four different melodies: the standard melody, the training melody, and two test melodies. During the training phase, all infants heard binaural pre-

\footnotetext{
${ }^{1}$ Sound intensity for the small headphones was measured with a circumaural earphone coupler and thus may have been slightly different than $70 \mathrm{~dB}$ but was constant across all infants. During pilot testing, melodies were presented to adults through the headphones to ensure sound quality.
} 
sentations of the standard melody and the training melody. The training melody had the same first and last notes as the standard melody, but the remaining notes differed from the standard melody in both contour and range (Table 1). During the test phase, infants heard the standard melody that had been presented during the training phase and one of the two test melodies - that is, either a contour-altered melody or a contourpreserved melody. For the two test melodies, the first and last notes were the same as those in the standard melody, and the second through fifth notes were changed. In the contour-altered melody, the changed notes altered the overall direction of the melodic contour, relative to the standard melody. In the contour-preserved melody, note changes were comparable in magnitude to those in the contour-altered melody (i.e., 2 to 4 semitones) but did not change the direction of the melodic contour (Table 1).

\section{Procedure}

The purpose and procedure of the study was explained to the parent, and their consent was obtained. The parent held the infant on their lap, facing the experimenter. Both the parent and the experimenter wore headphones through which classical music was played to mask their detection of the melodies that the infant was hearing. The task used in this study was adapted from the visually reinforced head-turn procedure (Trehub et al., 1984). In the typical visually reinforced head-turn procedure, the sound source is located near the toy case. Because we were interested in lateralization, the sound was presented to the infant through headphones to allow for monaural presentation. The task was divided into a training phase and a test phase.

Training phase. The experimenter dangled a small toy to induce the infant to look straight ahead. The standard melody was presented binaurally to the infant through headphones. The training melody was interspersed among presentations of the standard melody (as in Trehub et al., 1984) in a ratio of 1:2, such that at least one repetition of the standard melody occurred between each presentation of the training melody. Each trial consisted of the presentation of one melody, either the standard melody or the training melody. The training melody was initially presented at an intensity level $15 \mathrm{~dB}$ louder than the standard melody. Immediately after each occurrence of the training melody, one of the mechanized toy reinforcers was activated for $4 \mathrm{~s}$. The experimenter then attracted the infant's gaze back to midlinc. If the infant turned his or her head toward the case containing the toy reinforcer, the experimenter

Table 1

Stimulus Melodies for Experiments 1 and 2

\begin{tabular}{lcc}
\hline $\begin{array}{c}\text { Melody } \\
\text { type }\end{array}$ & \multicolumn{1}{c}{$\begin{array}{c}\text { Musical } \\
\text { notes }\end{array}$} & $\begin{array}{c}\text { Pitch direction } \\
\text { changes }\end{array}$ \\
\hline Standard sequence & Experiment 1 & \\
Training sequence & $\mathrm{C}_{3} \mathrm{D}_{3} \mathrm{E}_{3} \mathrm{G}_{3} \mathrm{~F}_{3} \mathrm{C}_{3}$ & +++-- \\
Contour preserved & $\mathrm{C}_{3} \mathrm{~A}_{2} \mathrm{~F}_{2} \mathrm{D}_{3} \mathrm{G}_{3} \mathrm{C}_{3}$ & --++- \\
Contour altered & $\mathrm{C}_{3} \mathrm{E}_{3} \mathrm{G}_{3} \mathrm{~A}_{3} \mathrm{D}_{3} \mathrm{C}_{3}$ & +++-- \\
& $\mathrm{C}_{3} \mathrm{~B}_{2} \mathrm{D}_{3} \mathrm{E}_{3} \mathrm{~A}_{2} \mathrm{C}_{3}$ & -++-+ \\
\hline & $\mathrm{Experiment}_{2}$ & \\
Standard sequence & $\mathrm{C}_{3} \mathrm{~A}_{2} \mathrm{D}_{3} \mathrm{~B}_{3} \mathrm{G}_{3} \mathrm{C}_{3}$ & -++-- \\
Training sequence & $\mathrm{C}_{3} \mathrm{D}_{3} \mathrm{E}_{3} \mathrm{G}_{2} \mathrm{~A}_{3} \mathrm{C}_{3}$ & ++-+- \\
Contour preserved & $\mathrm{C}_{3} \mathrm{~B}_{2} \mathrm{~F}_{3} \mathrm{G}_{3} \mathrm{D}_{3} \mathrm{C}_{3}$ & -++-- \\
Contour altered & $\mathrm{C}_{3} \mathrm{D}_{3} \mathrm{C}_{3} \mathrm{G}_{3} \mathrm{~F}_{3} \mathrm{C}_{3}$ & +-+-- \\
\hline
\end{tabular}

Note. The + or - symbols indicate the direction of change in pitch direction from one note to the next within each melody. The numerical subscripts represent the octave for each note, with $\mathrm{C}_{3}(131 \mathrm{~Hz})$ representing an octave below middle $\mathrm{C}$ (i.e., middle $\mathrm{C}$ is $\mathrm{C}_{4}$ ). activated a switch that signaled an observer in the control room. When the infant responded during a training melody, the computer instructed the observer to activate a toy reinforcer. No toys were activated if the head turn occurred during a standard melody. If the infant responded correctly on two consecutive trials, either by turning to the training melody or by not turning to the standard melody, the intensity level of the training melody was lowered to $10 \mathrm{~dB}$ louder than the standard. This procedure was repeated at $5 \mathrm{~dB}$ louder than the standard melody, and at an equal intensity level as the standard. However, if the infant did not turn on four training melodies in a row, the intensity level was increased to the previous level, and the process was repeated. The training criterion was met if the infant responded correctly on three consecutive trials, when the training melody was at an intensity level equal to that of the standard melody.

Trials were interrupted if the infant's headphones moved out of correct placement or if the infant became fussy, and the procedure was subsequently resumed if possible. In several instances, the parent held the infant's hands to dissuade her or him from reaching for the headphones. If the infant did not meet the training criterion within 90 trials, the session was stopped. The numbers of training trials for the accepted infants ranged from 30 to $89(M=58)$. Once the training criterion was reached, the test phase was initiated.

Test phase. During the test phase, infants heard the same repeating standard melody that they had heard in the training phase on trials interspersed with trials of a test melody. Infants were assigned randomly to one of the two test melody conditions (contour-altered change or contour-preserved change), with the constraint that equal numbers of girls and boys were tested in each condition. Each trial consisted of the presentation of one melody, either the standard melody or the test melody. The melodies were presented monaurally to the infant's left and right ears in a pseudorandom order, such that two test trials did not occur consecutively. The same trial order of left- and right-ear presentations was used for all infants. The computer instructed the observer to activate a toy reinforcer only if the experimenter's signal that the infant turned his or her head accurred during the test melody or within the $800 \mathrm{~ms}$ following offset of the test melody. If the head turn occurred during a standard melody, no toys were activated. The test phase consisted of 50 trials, which included 10 test melodies to each ear and 15 standard melodies to each ear.

\section{Parent Questionnaire}

After the experiment, parents were asked whether they were right- or left-handed and whether their infant demonstrated any consistent hand preference.

\section{Data Analysis}

The infants' head turns were coded from videotape by a trained observer who was naive to the hypothesis and did not have information concerning the ear of presentation for the melodies. The observer coded whether a head turn occurred on each trial (test melody trials and standard melody trials). This coding was used to have comparable scoring methods for responses on test and standard melody trials because the computer program saved response information for test, but not standard, melody trials. Comparison of the observer's coding of each infant's head-turn responses on test melody trials with the computer's tallies indicated high reliability across the group of infants $(r=.93)$. For a subset of 14 infants, trial-by-trial comparisons of the observer's coding (head turn vs. no head turn), with the same coding by a second observer, yielded percentage agreement of .88 (Cohen's $\kappa=.68$ ). Infant statc was also coded from videotape, and trials in which the infant was fussy or in which the headphones were not properly in place $(<3 \%$ of all trials) were not included in the analysis. 
The dependent measure was a $d^{\prime}$ score, based on the proportion of head turns to test melodies (hits) and the proportion of head turns to standard melodies (false alarms). Mean proportions of hits and false alarms are reported for each study, for descriptive purposes. We followed the procedure adopted by Thorpe and Trehub (1989) of adding $1 / 2$ to the number of responses (and dividing by $N+1$ ) to avoid proportions of 0 or 1 in calculating $d^{\prime}$ scores. Separate $d^{\prime}$ scores were calculated for each infant for melodies presented to the right ear and melodies presented to the left ear.

\section{Results}

On test melody trials, the mean percentage of head turns was $45 \%$, and this hit rate exceeded the $18 \%$ mean false alarm rate for head turns on the standard melody trials. The analysis of variance for $d^{\prime}$ scores included test melody condition (contouraltered change or contour-preserved change), gender, and side of toy reinforcer (left or right) as between-subjects variables and ear (left or right) as the within-subjects variable. Overall performance did not differ between contour-altered and contourpreserved conditions ( $d^{\prime}=.78$ and .80 , respectively). Although the main effect of gender was not significant, the mean $d^{\prime}$ scores were in the direction of better performance by female than by male infants $\left(d^{\prime}=.88\right.$ and .70 , respectively $), F(1,32)=2.8$, $p=.10$.

There was a significant laterality effect, indicated by the interaction between melody condition and ear, $F(1,32)=10.83, p$ $<.003$. This asymmetry followed the pattern of better left-ear detection of contour-altered melody changes and better rightear detection of contour-preserved melody changes (Figure 2). Comparisons within each condition indicated the following effects: a left-ear advantage for infants in the contour-altered melody condition, $F(1,16)=4.14, p<.06$, and a right-ear advantage for infants in the contour-preserved melody condition, $F(1$, $18)=7.16, p<.02$. There were no other significant effects or interactions.

To test whether infants' detection of melody changes exceeded chance levels of responding, $t$ tests comparing actual $d^{\prime}$ scores against a $d^{\prime}$ of 0 were calculated separately for each ear within each melody condition. Results confirmed that performance significantly exceeded chance, with $t(19)$ ranging from

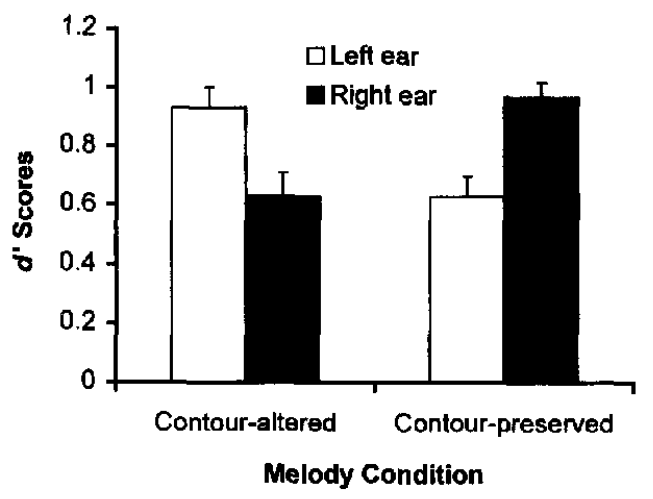

Figure 2. The $d^{\prime}$ scores for melodies presented to the left and right ears for infants in the contour-altered and contour-preserved conditions in Experiment 1. Error bars indicate $+1 S E$.
5.0 to $11.4(p<.0001)$, for each of the four conditions depicted in Figure 2.

To describe individual patterns of responses, the $d^{\prime}$ scores for left and right ears were compared for each infant. Of the 20 infants in the contour-altered condition, the majority ( $n=15$ ) showed a left-ear advantage, that is, higher $d^{\prime}$ for left-ear melody presentations than for right-ear presentations; the others ( $n=$ 5) showed the opposite pattern. A right-ear advantage for responding to contour-preserved test melodies occurred for 15 of the 20 infants in that condition; 3 infants showed the opposite pattern, and 2 infants showed no asymmetry.

\section{Discussion}

The results of this study are consistent with past evidence demonstrating that by 8.5 months, infants can discriminate changes in the overall contour of simple melodies as well as changes in notes and intervals that preserve the overall contour (Trehub et al., 1984). The key finding is that there were significant lateral asymmetries in perception of these different attributes of melodies. Infants detected changes that altered the contour of a melody better when the changed melody was presented to the left than to the right ear. Infants who heard changes that preserved the overall contour showed a right-ear advantage for detecting the changed melody. The infants' pattern of lateralization parallels that reported for adult detection of contour versus interval changes (e.g., Anderson, 1994; Peretz \& Morais, 1980).

The moderate sensitivities of infants in both test melody conditions probably reflects the difficulty of the learning task. The procedure required that infants learn an association between melody changes and the toy reinforcers without any correspondence between the location of the reinforcers and the sound source. The infants were able to learn this association during the training phase, and they continued to respond to melody changes during the test phase. Note that during the test phase, the infants experienced melody changes as well as changes in the input channel - that is, the ear of presentation. Despite the difficulty of the task, the infants' level of task performance was sufficient to reveal marked lateral asymmetries that were consistent across participants.

Although overall performance was slightly, but not significantly, better in female than in male infants, there was no indication of gender differences in lateral asymmetries. Previous studies of asymmetries in reaching behaviors in 6- to 8-month-olds (Lewkowicz \& Turkewitz, 1982) and in brain wave responses of 6-month-olds (Shucard \& Shucard, 1990) reported different types of gender-dependent patterns of lateral asymmetries to music and speech. It is difficult to reconcile the discrepant findings because of differences in stimuli, tasks, and response modalities among these studies. Also, it is not clear whether gender differences would be predicted in lateral asymmetries for melody processing in adults. Although studies of cognitive asymmetries in adults sometimes indicate greater lateralization in men than in women, results are inconsistent (Bradshaw \& Nettleton, 1983; Hellige, 1993).

In the present study, melody changes were defined as contour altered or contour preserved, but it is possible that the infants based their responses on some other cue. The range of notes was similar, but not identical, across the set of melodies: The 
contour-altered melody included two notes that were lower than those in the standard melody, and one note in the contour-preserved melody was higher than in the standard (Table 1). Infants can use pitch range to discriminate between melodies (Trehub et al., 1984, 1985). Could pitch differences account for the observed pattern of lateralization? Previc (1991) suggested that many results indicating left- or right-ear advantages could be explained by differences in absolute frequency, with left-ear advantages for high frequencies (although he was referring to frequencies $>1000 \mathrm{~Hz}$ ). In a different type of task, righthanded adults showed lateral asymmetries for relative pitch frequency, with a right-ear advantage when target stimuli were relatively higher in pitch compared to the average stimulus presented, and a-left-ear advantage for relatively lower pitch targets (Ivry \& Lebby, 1993). To verify that our results were due to lateral asymmetries in auditory pattern processing rather than to idiosyncratic attributes of the standard and test melodies, another experiment was conducted. For the new set of melodies used in Experiment 2, the range of notes in both the contouraltered and contour-preserved test melodies fell within the range of notes in the standard melody, and both the contour-preserved and contour-altered melodies introduced only one note that was not in the standard melody.

\section{Experiment 2}

\section{Method}

\section{Participants}

Forty healthy infants, 17 girls and 23 boys, were participants for this study. Infants were between the age of 7.5 and 9.5 months $(M=8.6$ months) and had no known hearing problems. Both parents of each infant were right-handed. An additional group of 8 infants with at least one left-handed parent participated in the study. Another 8 infants were excluded from the study because of equipment failure $(n=2)$ or because the infant did not reach the training criterion $(n=2)$ or did not complete the study due to fussiness ( $n=4)$. Infants were recruited in the Boston and Baltimore areas through newspaper advertisements and through letters sent to parents identified from state or published birth records.

\section{Stimuli}

A different set of standard, training, and test melodies was used in this study (Table 1), according to the constraints described for Experiment 1. The note changes were comparable in magnitude (i.e., 2 to 5 semitones) for the contour-preserved and contour-altered test melodies. The range of notes for the test melodies was within the range in the standard melody. Each test melody introduced one note that was not in the standard melody.

\section{Procedure}

The materials and procedure for this study were the same as in Experiment 1 . The number of training trials required for infants in this study ranged from 37 to $87(M=58)$. The pseudorandom trial order of leftear and right-ear presentations during the test phase was different than that in Experiment 1 and was constant for all infants. Side of toy reinforcer presentation was counterbalanced across infants and within conditions, with one exception: In the contour-preserved condition, toys were on the left side for 9 infants and on the right side for 11 infants.

\section{Data Analysis}

Because the available sample did not include equal numbers of male and female infants, gender was not included as a variable in the statistical analysis. $^{2}$

\section{Results}

Infants' head turns toward the toy reinforcer case occurred more frequently during test melody trials (hits, $M=46 \%$ ) than during standard melody trials (false alarms, $M=21 \%$ ). The overall analysis of variance for $d^{\prime}$ scores included test melody condition (contour altered vs. contour preserved), and side of toy reinforcer (left or right) as between-subjects variables and ear (left vs. right) as a within-subjects variable. There was a main effect of condition in this study. Overall performance was better in the contour-altered melody condition than in the contour-preserved melody condition $\left(d^{\prime}=.83\right.$ and .53 , respectively), $F(1,36)=5.26, p<.03$.

The lateralization effect was in the predicted direction and was significant, $F(1,36)=24.37, p<.001$, for the interaction of condition and ear (Figure 3). Follow-up analyses within each condition indicated a left-ear advantage for infants who heard contour-altered melodies, $F(1,18)=12.50, p<.003$, and a right-ear advantage for infants who heard contour-preserved melodies, $F(1,18)=11.97, p<.003$.

Follow-up $t$ tests indicated that $d^{\prime}$ scores significantly exceeded chance $\left(d^{\prime}=0\right)$ levels for each condition depicted in Figure $3, t(19)$ ranged from 3.02 to $8.69, p<.008$.

In descriptive analyses of individual patterns of responses in the contour-altered melody condition, 16 of 20 infants showed a left-ear advantage and 4 infants showed the opposite pattern. A right-ear advantage occurred for 16 of the 20 infants in the contour-preserved condition; 3 infants showed the opposite pattern and 1 infant did not show asymmetry.

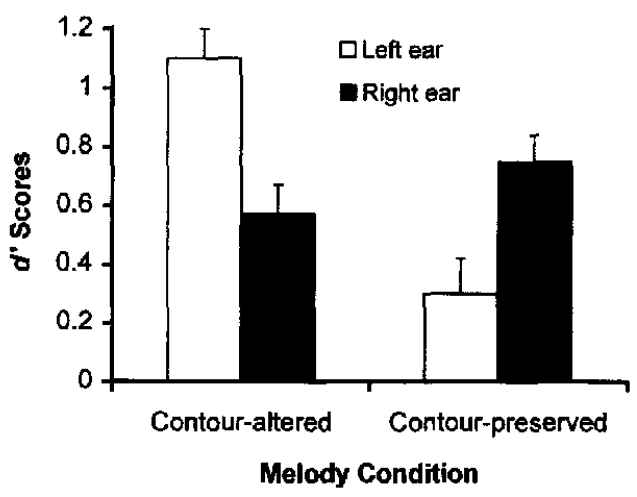

Figure 3. The $d^{\prime}$ scores for melodies presented to the left and right ears for infants in the contour-altered and contour-preserved conditions in Experiment 2. Error bars indicate $+1 S E$.

\footnotetext{
${ }^{2}$ As in Experiment 1, means were in the direction of better performance for female infants than for male infants $\left(d^{\prime} \mathrm{s}=.76\right.$ and .62 , respectively).
} 


\section{Supplemental Data: \\ Infants With Left-Handed Parent or Parents}

Data from infant participants who had one or two left-handed parents were examined separately. Across the two experiments, these data included 10 infants ( 5 girls, 5 boys) in the contouraltered melody conditions and 7 infants ( 4 girls, 3 boys) in the contour-preserved melody conditions. The pattern of performance on left- versus right-ear presentations for these infants did not resemble the pattern found for the groups of infants whose parents were both right-handed. In the contour-altered conditions, the mean $d^{\prime}$ scores for the infants with left-handed parent $(\mathrm{s})$ were similar for left-ear melodies $\left(d^{\prime}=.76\right)$ and right-ear melodies $\left(d^{\prime}=.70\right)$. For the contour-preserved conditions, the mean $d^{\prime}$ scores for the infants with left-handed parent(s) were .72 for left-ear melodies and .58 for right-ear melodies. This pattern is opposite to the marked right-ear advantage for the infants with right-handed parents tested in the contourpreserved conditions of the two experiments. Perhaps this is due to the higher probability that infants with left-handed parent ( $\mathrm{s}$ ) would eventually develop left-handed preferences. Hellige (1993) noted that hemispheric asymmetries are often reduced in left-handed participants when compared with right-handed participants because of variability in the strength and direction of lateralization in the left-handers. The handedness of most of the infants in our samples could not be ascertained reliably at 8.5 months. For the infants with right-handed parents, the percentages of parents reporting right, left, and no obvious hand preferences in their infant were $34 \%, 12 \%$, and $54 \%$, respectively. The corresponding percentages of $29 \%, 18 \%$, and $53 \%$ indicated a relatively comparable distribution in the group of infants of left-handed parent(s). Because this data set included only a small number of infants with left-handed parents, possible differences in infant task performance as a function of parent handedness should be considered speculative and interpreted with caution.

\section{Discussion}

The patterns of lateral asymmetries for the infants of righthanded parents in this study replicated the left-ear advantage for contour-altered changes and the right-ear advantage for contourpreserved changes found in Experiment 1. Examination of the records of individual infants indicated that the responses of a majority of the infants conformed to the predicted lateralization effects. The fact that the same pattern of asymmetries was obtained in another group of infants tested with a different set of melodies extends the generalizability of these findings and refutes an explanation of the phenomenon solely on the basis of the relative pitch frequencies of the notes within the standard and test melodies. Across the two experiments, infants of righthanded parents showed a pattern of lateral asymmetries that resembled the pattern described in adults-namely, a left-ear advantage for processing contour information and a right-ear advantage for processing interval information.

\section{General Discussion}

Infants' perception of melodic change reflects a right-hemisphere bias for processing contour information and a left-hemi- sphere bias for processing interval information in melodies. At 8.5 months, infants of right-handed parents were better able to detect changes that altered the contour of simple melodies when those changes were presented monaurally to the left compared to the right ear. Conversely, they were better able to detect changes that altered the pitch relations between adjacent notes, but not the overall contour of the melody, when those changes were presented monaurally to the right compared to the left ear. We interpret this pattern of lateralization in melody perception as indicative of hemispheric specialization for different components of auditory perceptual processing. The pattern of lateral asymmetry demonstrated by the infants is consistent with previous reports of hemispheric specialization in normal adults (e.g., Anderson, 1994; Peretz \& Morais, 1980).

In Experiment 2, infants in the contour-altered condition performed better overall than infants in the contour-preserved condition. This is consistent with previous findings in infants (Trehub et al., 1984), children (Morrongiello, Trehub, Thorpe, \& Capodilupo, 1985), and adults (Peretz \& Morais, 1988; Zatorre, 1985). This effect was not obtained in Experiment 1 , perhaps, because the higher pitch range for the contourpreserved melody change increased the salience of that change relative to the contour-altered melody change. In both experiments, the differences between standard and test melodies involved changing four of the six notes; such changes would be highly salient to adult listeners. More subtle discriminations (e.g., a change in one note) might produce a robust advantage for detection of contour-altered melody changes relative to contour-preserved changes.

It would be interesting to investigate what would happen to the pattern of lateral asymmetries if infants were tested with changes to transposed melodies - that is, melodies changed to a different pitch level. Adults exhibit a right-hemisphere advantage for detecting changes in transposed melodies (Peretz, 1987). To successfully detect contour-altered changes in such a task, infants could not rely on the absolute pitch cues. Trehub and colleagues (Trehub et al., 1987) demonstrated that infants can discriminate melodic contour while ignoring overall variations in pitch level during a learning task.

Studies of younger infants would also be of interest because a younger population might use different processing strategies for detecting change in contour-altered and contour-preserved melodies. On a practical note, investigation of younger infants' ability to make the type of melody discriminations tested in this study might require a different methodological approach because presentation of lateralized sounds via headphones increases the difficulty of training the visually reinforced headturn response. In addition, the memory and motor demands of the task are not suited for very young infants. Thus, whether the lateral asymmetries for contour-altered and contour-preserved melody changes exist in infants younger than 8.5 months remains to be determined.

Observations of adults suggest that the influence of listening strategy could prove relevant in measuring the development of asymmetries for subsystems of musical processing. Peretz and colleagues (Peretz \& Babai, 1992; Perez \& Morais, 1988) observed a left-ear advantage for contour information and a rightear advantage for interval information in musicians and nonmusicians, but an earlier study reported a right-ear advantage in 
musicians and a left-ear advantage in nonmusicians in a musical pattern identification task (Bever \& Chiarello, 1974). This difference between adult musicians and nonmusicians reflects the possibility that experience or listening strategy influences asymmetries in musical processing. For cxample, musicians are believed to preferentially attend to specific musical features such as interval information, whereas nonmusicians preferentially attend to global musical features such as contour (Morrongiello \& Roes, 1990; Morrongiello, Roes, \& Donnelly, 1989). Indeed, Peret $z$, Morais, and Bertelson (1987) reported that manipulating the instructions of a melody recognition task can alter the ear advantage: A right-ear advantage was found in nonmusicians when the task instructions involved looking for one note as opposed to focusing on the melody as a whole. This finding can be seen as consistent with a left-hemisphere advantage for processing interval information.

In addition to contributing to an understanding of the unfolding of asymmetries associated with components of melodic processing, this work is consistent with theories of lateralization of global and local perceptual processing. This global versus local distinction is of a hicrarchical nature: Global features refer to an object in its entirety, and local features refer to parts comprising the whole. Often features can be perceived and processed as either global or local, depending on context (Hellige, 1993). To the extent that contour-altered melody changes are discriminated on the basis of extraction of pattern or configural information, the relation between contour-altered and contourpreserved melody changes is reminiscent of the distinction between global and local processing. That is, contour-altered changes could be considered changes at the global level of melody shape, and contour-preserved changes occur at the more local level of interval changes. The usefulness of this distinction between global and local processing has been questioned, in part, because the terms have been used to describe various stimulus differences, strategy differences, or both across studies. However, the same direction of lateral asymmetries in global and local processing of hierarchical visual patterns has been described for adults (van Kleeck, 1989), patients with unilateral brain damage (Robertson \& Delis, 1986), and infants (Deruelle $\&$ de Schonen, 1991). This is consistent with the pattern of lateral asymmetries observed in our melody perception studics in infants and in previous studies in right-handed adults (e.g., Anderson, 1994; Peretz \& Morais, 1980).

The current results complement a growing body of evidence indicating functional specialization of the cerebral hemispheres in infancy. Furthermore, the identical pattern of lateralization in infants and adults is important for an understanding of the ontogeny of lateralization. Do neural asymmetries develop or unfold throughout the life span? A development of asymmetries implies that patterns of lateralization change (by either increasing or decreasing in degree, or by changing in direction) throughout maturation, whereas an unfolding of asymmetries suggests that patterns of direction and degree of asymmetries existing at or prior to birth are constant throughout life. Unfolding theories acknowledge that as cognitive ability increases, the situations in which functional lateralization are observed also increase. Conversely, as functional plasticity decreases with age, measurcs of functional lateralization will be affected. These need not necessarily reflect a maturational change in the pattern of hemispheric specialization (Witelson, 1987).

A developmental gradient between the two hemispheres, which has been observed both behaviorally and morphologically, need not be interpreted as evidence against the unfolding of cerebral asymmetries. Initially, theories of asymmetric hemisphere maturation proposed a left-to-right developmental gradient (Corballis \& Morgan, 1978). More recently, however, theories of right-to-left developmental gradients in morphology and function have been proposed (Galaburda, Sanides, \& Geschwind, 1978; Turkewitz, 1988). For example, aspects of language processing (Brown \& Jaffe, 1975) and development of cortical fissures (Dooling, Chi, \& Gilles, 1983) exhibit earlier development in the right hemisphere than in the left.

Unfolding theories of hemispheric specialization do not require within-hemisphere developmental changes to be constant throughout development. For example, observations of aphasic patients suggest that damage to comparable regions of the left hemisphere at various ages results in different types of aphasic deficits (Brown \& Jaffe, 1975). More specifically relevant to our studies is the indication that hemispheric specialization for melodic contours may be weakened or disrupted during early adolescence, and that similar disruptions occur in the processing of visual patterns and faces (Anderson, 1994; Carey, Diamond, \& Woods, 1980). Although these findings suggest possible developmental changes in components or subsystems within the left hemisphere for language processing and within the right hemisphere for music and face recognition, they do not support a change in the relative direction of hemisphere dominance for these processing specializations.

In addition, unfolding theories do not preclude maturational changes in interhemispheric processing. The fiber tracts connecting the two hemispheres mature slowly, with complete myelinization occurring only at puberty (Lecours, 1975). Deruelle and de Schonen (1991, p. 172) noted that during infancy, "the collaboration or time sharing between the hemispheres probably does not work in the same way as in adults." The similar direction of hemispheric specialization for melody perception seen in infants and adults indicates that asymmetric contributions to the processing of contour-altered and contour-preserved information are invariant throughout development. These results do not indicate that the interhemispheric interactions necessary for such musical processing are invariant or that the interhemispheric rate of transfer of such information is unchanging.

The finding of lateralization for different aspects of melody perception at 8.5 months extends our understanding of auditory processing components. Previous studies demonstrated right-ear advantages for processing speech and left-ear advantages for processing music in neonates (Bertoncini et al., 1989; Molfese \& Molfese, 1979). This work illustrates the advantages gained by examining specific aspects of such broadly defined functions as music processing. For example, because specializations for different subsystems of melody processing were found to be lateralized in different directions, the contribution of both hemispheres for musical processing warrants recognition.

Although lateralization patterns are of interest on their own, it is important to question why such asymmetries exist. A difficulty in considering functional explanations for behavioral asymmetries is the possibility that the circuitry underlying the 
behavior of interest evolved for a different purpose. For instance, the system underlying the detection of modulatory aspects of melody may be the same system responsible for detecting prosody in speech. Exaggerated prosody is a characteristic of infantdirected speech and, early in development, infants demonstrate preferences for infant-directed over adult-directed speech (Cooper \& Aslin, 1990; Fernald, 1992; Fernald \& Kuhl, 1987). Similarities between the processing of contours in melodies and the processing of prosody in speech suggest that fundamental components for the organization of auditory perception influences both music and speech. Trehub and Trainor (1993) suggested that music and speech "capitalize on inherent or universal principles of auditory pattern processing" (p. 142). Thus, it would be particularly interesting to determine whether the lateral asymmetries found for aspects of melody perception in 8.5month-old infants extend to the processing of other patterned auditory information.

\section{References}

Anderson, L. M. (1994). Brain specialization for melodic processing: A developmental comparison of auditory and visual patterns. Unpublished doctoral dissertation, Harvard University.

Behrens, S.J. (1985). The perception of stress and lateralization of prosody. Brain and Language, 26, 332-348.

Bertoncini, J., Morais, J., Bijeljac-Babic, R., McAdams, S., Pcretz, I., \& Mehler, J. (1989). Dichotic perception and laterality in neonates. Brain and Language, 37, 591-605.

Best, C. T. (1988). The emergence of cerebral asymmetries in carly human development: A literature review and a neuroembryological model. In D. L. Molfese \& S. J. Segalowitz (Eds.), Brain lateralization in children: Developmental implications (pp. 5-34). New York: Guilford Press.

Best, C. T., Hoffman, H., \& Glanville, B. B. (1982). Development of infant ear asymmetries for speech and music. Perception and Psychophysics, 31, 75-85.

Bever, T. G., \& Chiarello, R. (1974, Angust 9). Cerebral dominance in musicians and nonmusicians. Science, 185, 537-539.

Bradshaw, J. L., \& Nettleton, N. C. (1981). The nature of hemispheric specialization in man. Behavioral and Brain Sciences, 4, 51-9l.

Bradshaw, J. L., \& Nettleton, N. C. (1983). Human cerebral asymmetry. Englewood Cliffs, NJ: Prentice-Hall.

Brown, J. W., \& Jaffe, J. (1975). Note: Hypothesis on cerebral dominance. Neuropsychologia, 13, 107-110.

Carey, S., Diamond, R., \& Woods, B. (1980). Development of face recognition-A maturational component? Developmental Psychology, 16, 257-269.

Cooper, R. P., \& Aslin, R. N. (1990). Preference for infant-directed speech in the first month after birth. Child Development, 61, 15841595.

Corballis, M. C., \& Morgan, M. J. (1978), On the biological basis of human laterality: I. Evidence for a maturational left-right gradient. Behavioral and Brain Sciences, 1, 261-269.

Coren, S. (Ed.). (1990). Left-handedness: Behavioral implications and anomalies. Advances in psychology, vol. 67. Amsterdam: NorthHolland.

Deruelle, C., \& de Schonen, S. (1991). Hemispheric asymmetries in visual pattern processing in infancy. Brain and Cognilion, 16, 151179.

Deruelle, C., \& de Schonen, S. (1995). Pattern processing in infancy: Hemispheric differences in the processing of shape and location of visual components. Infant Behavior and Development, 18, 123-132.

Dooling, E. C., Chi, J. G., \& Gilles, F. H. (1983). Telencephalic develop- ment: Changing gyral patterns. In F. H. Gilles, A. Leviton, \& E. C. Dooling (Eds.), The developing human brain: Growth and epidemiologic neuroputhy. Boston: John Wright, PSG.

Dowling, W. J. (1978). Scale and contour: Two components of a theory of memory for melodies. Psychological Review, 85, 341-354.

Dowling, W. J. ( 1982). Melodic information processing and its development. In D. Deutsch (Ed.), The psychology of music (pp. 413-429). New York: Academic Press.

Dowling, W. J., \& Harwood, D. (1986). Music cognition. New York: Academic Press.

Ferland, M. B., \& Mendelson, M. J. (1989). Infants' categorization of melodic contour. Infant Behavior and Development, 12, 341-355.

Fernald, A. (1992). Human maternal vocalizations to infants as biologically relevant signals: An evolutionary perspective. In J. H. Barlow, L. Cosmides, \& J. Tooby (Eds.), The adapted mind (pp. 391-428). New York: Oxford University Press.

Fernald, A., \& Kuhl, P. (1987). Acoustic determinants of infant preference for motherese speech. Infant Behavior and Development, 10 , 279-293.

Galaburda, A. M., Sanides, F., \& Geschwind, N. (1978). Human brain: Cytoarchitectonic left-right asymmetries in the temporal speech region. Archives of Neurology, 35, 812-817.

Hellige, J. B. (1993). Hemispheric asymmetry: What's right and what's left? Cambridge, MA: Harvard University Press.

Hiscock, M., \& Kinsbourne, M. (1995). Phylogeny and ontogeny of cerebral lateralization. In R. J. Davidson \& K. Hugdahl (Eds.), Brain asymmetry. Cambridge, MA: MIT Press.

Huttenlocher, P. R. (1993). Synaptogenesis, synapse elimination, and neural plasticity in human cerebral cortex. In C. A. Nelson (Ed.), Threats to optimal development: Integrating biological, psychological, and social risk factors. Minnesota Symposium on Child Psychology (Vol. 27, pp. 35-54). Hillsdale, NJ: Erlbaum.

Ivry, R. B., \& Lebby, P. C. (1993). Hemispheric differences in auditory perception are similar to those found in visual perception. Psychological Science, 4, 41-45.

Kinsbourne, M., \& Hiscock, M. (1977). Does cerebral dominance develop? In S. Segalowitz \& F. Gruber (Eds.), Language development and neurological theory (pp. 172-188). New York: Academic Press.

Kitterle, F. L., Hellige, J. B., \& Christman, S. (1992). Visual hemispheric asymmetries depend on which spatial frequencies are task relevant. Brain and Cognition, 20, 308-314.

Kosslyn, S. M., Koenig, O., Barrett, A., Cave, C. B., Tang, J., \& Gabrieli, J. D. E. (1989). Evidence for two types of spatial representations: Hemispheric specialization for categorical and coordinate relations. Journal of Experimental Psychology: Human Perception and Performance, $15,723-735$.

Lecours, A. R. (1975). Myelogenetic correlates of the development of speech and language. In E. H. Lenneberg \& C. Lenneberg (Eds.), Foundations of language development: A multidisciplinary approach (Vol. 1, pp. 121-135). New York: Academic Press.

LeMay, M., \& Culebras, A. (1972). Human brain: Morphological differences in the hemispheres demonstrable by carotid arteriography. New England Journal of Medicine, 287, 168-170.

Lenneberg, E. H. (1967). Biological foundations of language. New York: Wiley.

Lewkowicz, D. J., \& Turkewitz, G. (1982). Influence of hemispheric specialization in sensory processing on reaching in infants: Age and gender related effects. Developmental Psychology, 18, 301-308.

McManus, I. C., \& Bryden, M. P. (1991). The genetics of handedness, cerebral dominance, and lateralization. In I. Rapin \& S. J. Segalowitz (Eds.), Handbook of neuropsychology (pp. 115-144). Amsterdam: Elsevier.

Molfese, D. L., \& Molfese, V. J. (1979). Hemisphere and stimulus dif- 
ferences as reflected in the cortical responses of newborn infants to speech stimuli. Developmental Psychology, 15, 505-511.

Molfese, D. L., \& Molfese, V. J. (1980). Cortical responses of preterm infants to phonetic and nonphonetic speech stimuli. Developmental Psychology, 16, 574-581.

Morrongiello, B. A. (1988). The development of auditory pattern perception skills. In C. Rovee-Collier (Ed.), Advances in infancy research (Vol. 5, pp. 135-172). Norwood, NJ: Ablex.

Morrongiello, B., \& Roes, C. (1990). Developmental changes in children's perception of musical sequences: Effects of musical training Developmental Psychology, 26, 814-820.

Morrongiello, B., Roes, C., \& Donnelly, F. (1989). Children's perception of musical patterns: Effects of music instruction. Music Perception, 6, 447-462.

Morrongiello, B., Trehub, S., Thorpe, L., \& Capodilupo, S. (1985). Children's perception of melodies: The role of contour, frequency. and rate of presentation. Journal of Experimental Child Psychology, 40, 279-292.

Peretz, I. (1987). Shifting ear-asymmetry in melody comparison through transposition. Cortex, 23, 317-323.

Peretz, I. (1990). Processing of local and global musical information by unilateral brain-damaged patients. Brain, 113, 1185-1209.

Peretz, I. (1993). Auditory agnosia: a functional analysis. In S. McAdams \& E. Bigand (Eds.), Thinking in sound: The cognitive psychol. ogy of human audition (pp. 199-230). New York: Clarendon Press.

Peretz, I., \& Babai, M. (1992). The role of contour and intervals in the recognition of melody parts: Evidence from cerebral asymmetries in musicians. Neuropsychologia, 30, 277-292.

Peretz, I., \& Morais, J. (1980). Modes of processing melodies and earasymmetry in nonmusicians. Neuropsychologia, 18, 477-489.

Peretz, I., \& Morais, J. (1988). Determinants of laterality for music: Towards an information processing account. In K. Hugdahl (Ed.), Handbook of dichotic listening: Theory, methods and research (pp. 323-358). New York: Wiley.

Peretz, I., Morais, J., \& Bertelson, P. (1987). Shifting ear differences in melody recognition through strategy inducement. Brain and Cognition, 6, 202-215.

Previc, F. H. (1991). A general theory concerning the prenatal origins of cerebral lateralization in humans. Psychological Review, 98, 299334.

Robertson, L. C., \& Delis, D. C. (1986). Part-whole processing in unilateral brain-damaged patients: Dysfunction of hierarchical organization. Neuropsychologia, 24, 363-370.

Ross, E. D. (1985). Modulation of affect and nonverbal communication by the right hemisphere. In M. Mesulam (Ed.), Principles of behavioral neurology (pp. 239-258). Philadelphia: F. A. Davis.

Shipley-Brown, F., Dingwall, W. O., Berlin. C. I., Yeni-Komshian, G., \& Gordon-Salant, S. (1988). Hemispheric processing of affective and linguistic intonation contours in normal subjects. Brain and Language, $33,16-26$.

Shucard, J. L., \& Shucard, D. W. (1990). Auditory evoked potentials and hand preference in 6-month-old infants: Possible gender-related differences in cerebral organization. Developmental Psychology, 26, 923-930.

Thorpe, L. A., \& Trehub, S. E. (1989). Duration illusion and auditory grouping in infancy. Developmental Psychology, 25, 122-127.

Trehub, S. E. (1993). Temporal auditory processing in infancy. In P. Tallal, A. M. Galaburda, R. R. Llinas, \& C. von Euler (Eds.), Temporal information processing in the nervous system (pp. 137-149). New York: New York Academy of Sciences.

Trehub, S. E., Bull, D., \& Thorpe, L. A. (1984). Infants' perception of melodies: The role of melodic contour. Child Development, 55, 821830.

Trehub, S. E., Thorpe, L. A., \& Morrongiello, B. A. (1985). Infants' perception of melodies: Changes in a single tone. Infant Behavior and Development, 8, 213-223.

Trchub, S. E., Thorpe, L. A., \& Morrongiello, B. A. (1987). Organizational processes in infants' perception of auditory patterns. Child Development, $58,741-749$.

Trehub, S. E., \& Trainor, L. J. (1990). Rules for listening in infancy. In J. T. Enns (Ed.), The development of attention: Research and theory (pp. 87-119). Amsterdam: Elsevier.

Trehub, S. E., \& Trainor, L. J. (1993). Listening strategies in infancy: The roots of music and language development. In S. McAdams \& E. Bigand (Eds.), Thinking in sound: The cognitive psychology of human audition (pp. 278-327). New York: Oxford University Press.

Trehub, S. E., Trainor, L. J., \& Unyk, A. M. (1993). Music and speech processing in the first year of life. In H. W. Reese (Ed.), Advances in child development (Vol. 24, pp. 1-35). New York: Academic Press.

Turkewitz, G. (1988). A prenatal source for the development of hernispheric specialization. In D. L. Molfese \& S. J. Segalowitz (Eds.), Brain lateralization in children: Developmental implications (pp. 7381). New York: Guilford Press.

van Kleeck, M. H. (1989). Hemispheric differences in global versus local processing of hierarchical visual stimuli by normal subjects: New data and a meta-analysis of previous data. Neuropsychologia, $27,1165-1178$.

Witelson, S. F. (1987). Neurobiological aspects of language. Child Development, 58, 653-688.

Young, G. Y., \& Gagnon, M. (1990). Neonatal laterality, birth stress, familial sinistrality, and left-brain inhibition. Developmental Neuropsychology, 6, 127-150.

Zatorre, R. (1985). Discrimination and recognition of tonal melodies after unilateral cerebral excisions. Neuropsychologia, 23, 31-41.

Received April 19, 1995

Revision received May 22, 1997

Accepted May 22, 1997 